Gut, 1973, 14, 215-220

\title{
The nature and incidence of gallstones containing calcium
}

\author{
D. JUNE SUTOR AND SUSAN E. WOOLEY
}

From the Department of Chemistry, University College, London

SUMMARY The crystalline constituents of gallstones determined by $x$-ray powder diffraction can be broadly classified as cholesterols and calcium salts. On this basis there are three main types of stones consisting of cholesterol, calcium salts, and mixtures of these. In a study of the composition of 481 gallstones from 11 countries, the percentage incidence of each was $59 \cdot 9,13 \cdot 1$, and $27 \cdot 0$ respectively. The presence of calcium compounds in $40.1 \%$ of the calculi showed the importance of these constituents in the nucleation and/or growth of many specimens. Men are just as likely as women to form stones consisting entirely of calcium salts, but female patients outnumber males by about $3: 1$ for both calculi of cholesterol and those of cholesterol with calcium salts. A description is given of the appearance, texture, and structure of calcium-containing stones subdivided according to the calcium salt(s) present.

Although there has been an upsurge of interest in the aetiology of the cholesterol gallstone in the last few years, stones composed of other compounds have received little attention. In 1971, we reported the constituents which could occur in such calculi and showed they accounted for $29 \%$ of the total crystalline material in a collection of $\mathbf{3 3 1}$ gallstones, the remaining $71 \%$ of the material being cholesterol. No systematic study has, however, been conducted by us or other workers on the incidence of these stones, on their physical properties, such as appearance, structure, etc, or on the type of person likely to form them, and so the magnitude and nature of the problem which they constitute is largely unknown.

There is also no satisfactory system in common use at the present time of classifying these and other gallstones. Although our previous paper on composition (Sutor and Wooley, 1971) invalidated many of the old systems based on this method, unsuitable nomenclature is still often employed. In one such terminology, gallstones are referred to as cholesterol or pigment stones. This gives an erroneous picture of their composition since our $x$-ray analysis has shown that many of the cholesterol variety contain pigment; pigment is not usually the major constituent of the type bearing this name and mixtures of different constituents are frequently present.

Received for publication 8 January 1973.
As a result of a study of 481 gallstones from 11 countries, we suggest a more logical method of classification based on composition rather than on appearance or any other characteristic, and give the incidence and description of stones other than the cholesterol ones but inclading those containing mixtures of cholesterol with other compounds.

\section{Material and Method}

This study is based on a collection of 481 gallstones from the following 11 countries: America (87 stones), Australia (25), Brazil (25), England (129), Germany (51), India (19), Israel (10), Japan (29), Kuwait (35), South Africa (26), and Sweden (45) (table I).

The stones from each country were collected in sequence over a period of months or years as the patients underwent surgery for their removal. Specimens were only selected in the case of the German collection where, because of its size, every sixth one was studied. Details were not always available for the age and sex of the patient or the number of stones formed.

Each gallstone was split carefully in half so as not to damage or polish the broken surface, and the appearance and structure of the nucleus, interior and surface areas were examined with a stereozoom binocular microscope. The sequential deposition of the crystalline compounds in these areas was 


\begin{tabular}{|c|c|c|c|c|c|c|c|c|}
\hline Country & $\begin{array}{l}\text { Total Number } \\
\text { in Collection }\end{array}$ & $\begin{array}{l}\text { Number with } \\
\text { Calcium Salts }\end{array}$ & $\begin{array}{l}\text { Pure Calcium } \\
\text { Carbonate }\end{array}$ & $\begin{array}{l}\text { Pure Calcium } \\
\text { Palmitate }\end{array}$ & $\begin{array}{l}\text { Pure Calcium } \\
\text { Phosphate }\end{array}$ & $\begin{array}{l}\text { Pure Calcium } \\
\text { Bilirubinate }\end{array}$ & $\begin{array}{l}\text { Mixed Calcium } \\
\text { Salts }\end{array}$ & $\begin{array}{l}\text { Cholesterol }+ \\
\text { Calcium Salts }\end{array}$ \\
\hline America & 87 & 35 & 1 & 1 & 1 & 1 & 5 & 26 \\
\hline Australia & 25 & 11 & - & - & - & - & - & 11 \\
\hline Brazil & 25 & 9 & 2 & - & - & - & - & 7 \\
\hline England & 129 & 64 & 10 & 4 & 2 & 2 & 7 & 39 \\
\hline Germany & 51 & 3 & 2 & - & - & 1 & - & - \\
\hline India & 19 & 6 & - & - & - & - & 1 & 5 \\
\hline Israel & 10 & 1 & - & - & - & 1 & - & - \\
\hline Japan & 29 & 11 & - & - & 4 & 1 & 2 & 4 \\
\hline Kuwait & 35 & 22 & 2 & 2 & - & - & 1 & 17 \\
\hline South Africa & 26 & 20 & - & 3 & 1 & 1 & 5 & 10 \\
\hline Sweden & 45 & 11 & - & - & - & - & - & 11 \\
\hline Total & 481 & 193 & 17 & 10 & 8 & 7 & 21 & 130 \\
\hline
\end{tabular}

Table I Distribution in each country of the stones containing calcium salts

determined by $x$-ray powder diffraction using the techniques described previously (Sutor and Wooley, 1969, 1971).

\section{Classification of Gallstones According to Composition}

In previous papers, we have shown that the crystalline compounds which can occur in gallstones are cholesterol monohydrate, anhydrous cholesterol, cholesterol II (also anhydrous), the three forms of calcium carbonate-calcite, aragonite, and vateritethe two forms of calcium phosphate-apatite and whitlockite-calcium palmitate, sodium chloride, and $\alpha$-palmitic acid (Sutor and Wooley, 1971; Sutor and Gaston, 1972). No $x$-ray diffraction pattern, apart from a few unidentifiable diffuse bands, was obtained from the pigment present in most specimens and this material was assumed to be amorphous. Subsequently to these studies though, very small quantities of crystalline or almost colloidal calcium bilirubinate have been identified in a few stones some of which were originally thought to be completely amorphous.

Of these compounds, $\alpha$-palmitic acid is a rare constituent occurring in small quantities in only three stones and the sodium chloride found by us and other workers is likely to be an adventitious inclusion. It is soluble in bile and its presence in gallstones probably results from not washing off any bile or from soaking them in saline solution.

Apart then from $\alpha$-palmitic acid, the crystalline constituents fall naturally into two groups: first, the cholesterols, and secondly, the calcium salts. On this basis and ignoring the amorphous pigment, a broad general classification of gallstones would be: (1) pure cholesterol stones; (2) pure calcium-containing stones including those composed of mixtures of different calcium salts; (3) gallstones consisting of both cholesterol and calcium salts.

Studies on the conditions leading to the formation of the different calcium salts may show that further subdivision may be necessary according to the nature of the calcium salt present. Another important factor is the structure of calculi of mixed composition. This may eventually be of help in delineating their pathogenesis, as the composition of the nucleus is related to the factor(s) initiating crystallization. A gallstone with a nucleus of cholesterol and outer layers of calcium carbonate is likely to have a different aetiology from one with a nucleus of calcium carbonate and a surface deposit of cholesterol. But in the meantime, until all these aspects have been fully investigated, the suggested method of classification is simple and informative.

\section{Overall Incidence of Calcium Compounds}

Sixty-three of the stones $(13 \cdot 1 \%)$ consisted entirely of one or more of the calcium salts (table II). A further $130(27 \%)$ were composed of mixtures of cholesterol and compounds of calcium (table III), and in these, the nucleus, interior or surface areas might be composed of either or both of these types of compounds but the total amount of calcium salts irrespective of where they occurred in the stone was at least $5 \%$ of the crystalline material. In many of the remaining 288 'pure' cholesterol gallstones a very small amount (1-5\%) of calcium-containing material was present, generally as the rather curious small white beads of calcium palmitate (Sutor, 1970) whose origin is unknown. Crystalline calcium compounds were therefore present in more than trace amounts in $40.1 \%$ of the 481 gallstones, showing that calcium is an important factor in the nucleation and/or growth of many of them. The different types of calcium-containing stones subdivided according to the calcium salts present will now be discussed in detail. Data for those consisting entirely of calcium salts and the patients forming them are in table II and the corresponding information for ones of mixed composition is in table III. 


\begin{tabular}{|c|c|c|c|c|c|}
\hline Composition & Number of Stones & $\begin{array}{l}\text { Average Weight }(g) \\
\text { of Material/Patient }\end{array}$ & Females & Males & $\begin{array}{l}\text { Average Age }(y r) \\
\text { (Number of Values) }\end{array}$ \\
\hline $\begin{array}{l}\text { Calcium carbonate } \\
\text { Calcium palmitate } \\
\text { Calcium phosphate } \\
\text { Calcium bilirubinate } \\
\text { Calcium carbonate + palmitate } \\
\text { Calcium carbonate + phosphate } \\
\text { Calcium carbonate + bilirubinate } \\
\text { Calcium palmitate + phosphate } \\
\text { Calcium palmitate + bilirubinate } \\
\text { Calcium phosphate + bilirubinate } \\
\text { Calcium carbonate + palmitate }+ \text { phosphate } \\
\text { Calcium carbonate + palmitate }+ \text { bilirubinate }\end{array}$ & $\begin{array}{r}17 \\
10 \\
8 \\
7 \\
7 \\
3 \\
3 \\
3 \\
2 \\
1 \\
1 \\
1\end{array}$ & $\begin{array}{l}0.53 \\
0.73 \\
0 \cdot 70 \\
0.95 \\
1 \cdot 64 \\
3 \cdot 08 \\
1 \cdot 14 \\
0 \cdot 46 \\
1 \cdot 72 \\
0 \cdot 26 \\
0 \cdot 11 \\
\text { Fragments only }\end{array}$ & $\begin{array}{l}7 \\
5 \\
5 \\
2 \\
2 \\
2 \\
-3 \\
1 \\
- \\
-\end{array}$ & $\begin{array}{l}6 \\
4 \\
3 \\
5 \\
1 \\
2 \\
1 \\
1 \\
1 \\
-\end{array}$ & $\begin{array}{ll}53 \cdot 5 & (11) \\
64 \cdot 8 & (8) \\
43 & (3) \\
44 & (4) \\
60 \cdot 3 & (6) \\
64 & (2) \\
63 & (2) \\
73 & (2) \\
57 & (1) \\
- & \\
68 & (1) \\
- & \end{array}$ \\
\hline
\end{tabular}

Table II Data for the stones consisting entirely of calcium salts and for the patients forming them

\section{Calcium Carbonate Stones}

Seventeen stones were composed of crystalline calcium carbonate. Of these two were pure aragonite, one was calcite, four were a combination of calcite and vaterite, one was aragonite and vaterite, and nine were composed of all three forms of calcium carbonate. Ten were from England, the others from America, Germany, and Brazil (table I).

The patients were seven females and six males (the sex of four was not known), and they formed material ranging in weight from 0.04 to $3.00 \mathrm{~g}$ with an average value of $0.53 \mathrm{~g}$. Over half had more than one stone and two formed hundreds of tiny calculi accounting for some of the heavier samples. Apart from one rare octahedral-shaped specimen which weighed $3.00 \mathrm{~g}$, the stones themselves tended to be small with an average weight of $0.09 \mathrm{~g}$ and a weight range of 0.04 to $0.38 \mathrm{~g}$. The average age of the patients was 53.5 years (range 26-75 years).

Although the stone shape often varied from one patient to another, three samples were of faceted polyhedral specimens and six had small spine-like protuberances. The small spikes, only found in pure calcium carbonate and mixed cholesterol/calcium carbonate calculi, can be considered indicative of the presence of calcium carbonate. Three stones were round or ovoid in shape with slightly pitted surfaces and the regular octahedral-shaped one has already been mentioned. In the other cases, it was difficult to tell the original shape as only small fragments were provided.

In cross section, three gallstones were laminated with a fine-grained structure and a distinct nucleus. The others had no obvious nucleus and showed a variety of textures ranging fromaggregates of medium or coarse-grained crystals to coarse or fine-grained powders, and these were often associated with a region which was coal-like in appearance in that it had a similar fused structure which could be glasslike or dull.

All the stones were pigmented and were black, black-brown, or red-brown generally throughout, though some had lighter interiors and about half had small, frequently white, deposits on the surface. These were too small to scrape off and analyse by $x$-ray diffraction, and microscopically they bore no structural resemblance to the beads of calcium palmitate which were found in only one calcium carbonate stone, in the nucleus.

\section{Calcium Palmitate Stones}

There were 10 examples of this type of stone. The

\begin{tabular}{|c|c|c|c|c|c|}
\hline Composition & Number of Stones & $\begin{array}{l}\text { Average Weight }(g) \\
\text { of Material/Patient }\end{array}$ & Females & Males & $\begin{array}{l}\text { Average Age }(y r) \\
\text { (Number of Values) }\end{array}$ \\
\hline $\begin{array}{l}\text { Cholesterol + } \\
\text { calcium carbonate } \\
\text { calcium palmitate } \\
\text { calcium phosphate } \\
\text { calcium carbonate + palmitate } \\
\text { calcium carbonate + phosphate } \\
\text { calcium carbonate + bilirubinate } \\
\text { calcium carbonate + palmitic acid } \\
\text { calcium palmitate + phosphate } \\
\text { calcium palmitate + palmitic acid } \\
\text { calcium carbonate + palmitate + phosphate }\end{array}$ & $\begin{array}{r}93 \\
3 \\
8 \\
12 \\
5 \\
5 \\
2 \\
2 \\
3 \\
1 \\
1\end{array}$ & $\begin{array}{l}2 \cdot 68 \\
0 \cdot 68 \\
1 \cdot 79 \\
1 \cdot 84 \\
2 \cdot 57 \\
5 \cdot 85 \\
8 \cdot 04 \\
0 \cdot 30 \\
0 \cdot 10 \\
0 \cdot 25\end{array}$ & $\begin{array}{l}71 \\
3 \\
3 \\
7 \\
4 \\
2 \\
2 \\
1 \\
1 \\
-\end{array}$ & $\begin{array}{l}\frac{18}{5} \\
5 \\
\frac{1}{2} \\
-\end{array}$ & $\begin{array}{lr}51 & (74) \\
46 & (3) \\
57 & (2) \\
48 & (10) \\
47 & (5) \\
61 & (2) \\
65 & (2) \\
43 & (3) \\
- & \\
- & \end{array}$ \\
\hline
\end{tabular}

Table III Data for the stones consisting of mixtures of cholesterol and calcium salts and for the patients forming them 
amount of material from each patient ranged in weight from 0.07 to $3.26 \mathrm{~g}$ with an average value of $0.73 \mathrm{~g}$. Two patients formed only one stone but the exact number produced by the rest was not provided and could not be determined since only fragments or what appeared to be a stone and fragments were sent. The patients were five males and four females (one sex unknown) and their average age was 64.8 years (range 37-79 years).

All gallstones except one, which was cream in colour, had pigment present throughout and were red-brown, black, or black-brown in cross section. Their external appearance varied considerably; they were ovoid, round, or tetrahedral in shape and the surface could be smooth or rough, but protuberances were present on only one which had a slightly nodular appearance. In cross section they were usually laminated with a coarse or fine-grained texture. A distinct nucleus was present in four of these but generally this could not be differentiated and the central area appeared to be homogeneous. Small beads of calcium palmitate were often found in the nucleus and/or interior but not on the surface, and were typically white in colour regardless of the pigment present in the rest of the material.

\section{Calcium Phosphate Stones}

Of the eight stones consisting of calcium phosphate, four were of apatite, two of whitlockite, and two of mixed composition. Unfortunately, only fragments were provided in five cases but the remaining three samples, consisting of irregular-shaped multiple stones numbering eight, 12 , and 52 , were composed of apatite, whitlockite, and mixed apatite and whitlockite respectively. Such stones were small with an average weight of $0.05 \mathrm{~g}$, but the total amount of material formed per patient ranged from 0.26 to $1.78 \mathrm{~g}$. The five patients whose sex was known were all females but most of the ages were not provided.

The surfaces of the stones tended to be cracked in places and slightly nodular, and glass-like patches were present in some areas, but there was no correlation of these features with the type of calcium phosphate present since they appeared regularly in the apatite and/or whitlockite varieties. These gallstones were almost invariably black in colour throughout, only occasionally did this vary to a brownish or reddish black in the interior. In cross section they showed no structural features, such as laminations, distinct nuclei, etc, but were compact, rather like coal in appearance and texture, with dull and glassy areas. Small white calcium palmitate beads were embedded in the dark interiors of two of the pure apatite specimens.

\section{Calcium Bilirubinate Stones}

There were seven stones whose $x$-ray diffraction pattern corresponded to that of calcium bilirubinate. Some of these also contained amorphous material but this was likely to be calcium bilirubinate too. There was no example of a patient forming a single stone of this composition; the number ranged from five to many hundreds of small, irregularly shaped, nodular calculi. The nodules appeared to be the most important feature of this type. The average weight of material per patient was $0.95 \mathrm{~g}$ with a range of 0.18 to $2.96 \mathrm{~g}$, but the average weight of a stone was less than $0.01 \mathrm{~g}$. The average age of the patients was 44 years with a range of 39 to 53 years.

All stones were black in colour except one which had red, brown, and cream areas. The black ones had usually shiny or partly shiny surfaces and invariably shiny black interiors, rather like coal in appearance. As well as the nodules, heavy deposits of lightcoloured material were always present on the surfaces. Microscopically these were not calcium palmitate beads and their composition could not be determined by $x$-ray diffraction because the total amount of material was too small.

\section{Stones Composed of Mixed Calcium Salts}

Twenty-one stones were composed of calcium salts of two or three acid radicals, the most frequent combination being calcium carbonate and calcium palmitate (table II). No general description was applicable to this type or the others in this group because of the large number of combinations possible, the different sequences in which the compounds were laid down, and the frequent presence of intimate mixtures of several constituents.

\section{Stones of Cholesterol and Calcium Salts}

The different combinations of the calcium salts with cholesterol are shown in table III, together with the age and sex of the patients and the average weight of material formed. By far the most common combination was cholesterol and calcium carbonate, and the incidence of such stones was very high in the female population. The composition of the nucleus or, when this could not be distinguished, the interior of all the stones is given in table IV. Pure calcium salts comprised this area in only $10 \%$ of the cases, cholesterol accounted for $28.5 \%$ of the nuclei, while mixtures of these compounds were present in the remaining $61.5 \%$. In these mixtures it was not possible to tell whether a particular type of crystal was the nidus on which the rest of the stone grew or if aggregation of crystals of different composition had occurred. 


\begin{tabular}{|c|c|c|c|}
\hline \multirow[t]{2}{*}{ Overall Stone Composition } & \multicolumn{3}{|c|}{ Number of Stones with a Nucleus Composed of } \\
\hline & Cholesterol + Calcium Salts & Cholesterol & Calcium Salts \\
\hline $\begin{array}{l}\text { Cholesterol + } \\
\text { calcium carbonate } \\
\text { calcium palmitate } \\
\text { calcium phosphate } \\
\text { calcium carbonate + palmitate } \\
\text { calcium carbonate + phosphate } \\
\text { calcium carbonate + bilirubinate } \\
\text { calcium carbonate + palmitic acid } \\
\text { calcium palmitate + phosphate } \\
\text { calcium palmitate + palmitic acid } \\
\text { calcium carbonate + palmitate + phosphate }\end{array}$ & $\begin{array}{r}55 \\
3 \\
1 \\
10 \\
3 \\
2 \\
1 \\
3 \\
1 \\
1\end{array}$ & $\begin{array}{l}31 \\
3 \\
2 \\
1 \\
- \\
- \\
- \\
-\end{array}$ & $\begin{array}{r}7 \\
\overline{4} \\
\overline{1} \\
-1 \\
- \\
-\end{array}$ \\
\hline
\end{tabular}

Table IV Composition of the nucleus (or where this could not be distinguished, the interior) in stones consisting of both cholesterol and calcium salts

Calculi in this group could be single or multiple, and in shape they were round, ovoid, tetrahedral, polyhedral, or irregular, etc, but surface spikes were only associated with the presence of calcium carbonate, though not all stones containing this compound had this feature. In colour they were generally much lighter than those consisting entirely of calcium salts and in this respect they were difficult to differentiate from the pure cholesterol gallstones. However, a heavily pigmented area in a stone of mixed composition did not necessarily imply the presence of calcium compounds since a pure cholesterol nucleus, interior, or surface could be similarly blackened and sometimes had a texture like that of calciumcontaining material. Cholesterol is easily recognized when it occurs as radiating silky crystals but sometimes its texture can be granular and very like that in some of the stones of calcium salts.

\section{The Age and Sex of Calcium Stone Formers}

In tables II and III the age and sex of the patients are given. Almost equal numbers of males and females formed stones of calcium salts, whereas for calculi consisting of both cholesterol and calcium salts, the female patients outnumbered the males by $3: 1$. The difference in the numbers for the two groups was statistically significant $(P<0.01)$. In our previous study (Sutor and Wooley, 1971), the female to male ratio was 5:2 disregarding the composition of the stones formed, and these two ratios represent what is generally accepted as the approximate sex incidence. Males are therefore as likely to form stones of calcium salts as females, but less likely to form the cholesterol and the mixed cholesterol/calcium salt varieties.

The average age of the patients who formed calculi of calcium salts and of mixed composition was 57.5 and 50.3 years respectively. These figures apply only to the age at operation and do not represent the age when stone nucleation occurred which is the relevant but unavailable figure. Nevertheless, they were statistically different $(P<0.01)$ which may be indicative of some difference in stone aetiology. There was no significant difference in the average age of the calcium palmitate and calcium carbonate stone formers, nor in the average age of each of these compared with the group with stones consisting of both these calcium salts. Other groups were too small to test.

\section{Geographical Incidence of the Calcium-containing Stones}

The number of calcium-containing stones in most of the individual countries was too small to comment on any difference in incidence on a geographical basis (table I). In a statistical survey carried out on the overall composition of gallstones in eight of these countries but on a smaller number of stones (Sutor and Wooley, 1971), the composition distribution in each area was different. In particular the English collection contained significantly more calcium carbonate than any of the others, while collections from Kuwait, India, and South Africa had significantly larger amounts of calcium palmitate, calcium phosphate, and both calcium palmitate and calcium phosphate respectively. Since then the number of English gallstones analysed has increased from 47 to 129 and the trend in composition is still obvious. Calcium carbonate was the only constituent of 10 of these $(7.7 \%)$ and it occurred in four of the seven composed of mixed calcium salts and 35 of the 39 containing cholesterol and calcium. Clearly, calcium carbonate is a frequent constituent of English gallstones and a study of the incidence of calciumcontaining stones in other countries will be of interest when there are collections of a suitable size. 


\section{Identification of Calcium in Gallstones}

This survey has shown that although the gallstones consisting entirely of calcium salts can often be distinguished from the other types by physical characteristics such as colour, texture, etc, such properties cannot usually differentiate between the different salts present or indeed identify cholesterol in some cases. The nodular calcium bilirubinate stones with their coal-like appearance and the spiked calculi of calcium carbonate would probably be most easily recognized. However, to identify the different compounds present in gallstones with certainty, crystallographic techniques of polarizing microscopy or $x$-ray diffraction must be used. They have many advantages over other methods of analysis, such as chemical, in that they give the composition and crystal form of the material present.

We thank the Medical Research Council for financing this work.

\section{References}

Sutor, D. J. (1970). Calcium palmitate and a-palmitic acid in gallstones. Gut, 11, 618-619.

Sutor, D. J., and Gaston, P. J. (1972). Anhydrous cholesterol: a new crystalline form in gallstones. Gut, 13, 64-65.

Sutor, D. J., and Wooley, S. E. (1969). X-ray diffraction studies of the composition of gallstones from English and Australian patients. Gut, 10, 681-683.

Sutor, D. J., and Wooley, S. E. (1971). A statistical survey of the composition of gallstones in eight countries. Gut, 12, 55-64.

\section{The February 1973 Issue}

\section{THE FEBRUARY 1973 ISSUE CONTAINS THE FOLLOWING PAPERS}

Cholesterol and bile salt studies on the bile of patients with cholesterol gallstones F. HELLER AND IAN A. D. BOUCHIER

Lymphocyte transformation in response to phytohaemagglutinin in primary biliary cirrhosis: The search for a plasma inhibitory factor R. A. FOX, F. J. DUDLEY, M. SAMUELS, J. MILligAN, AND SHEILA SHERLOCK

Ulcerative colitis and carcinoma of the proximal bile ducts ALEXANDER P. ROSS AND JOHN W. BRAASCH

The use of isolated cells to assess the contribution of the mucosal epithelium to the metabolism of the intestinal wall E. M. EVANS AND K. BURDETT

The effect of azathioprine on gastric mucosal histology and acid secretion in chronic gastritis A. D. JORGE AND D. SANCHEZ

The relation between gastric acid secretion and body habitus, blood groups, smoking, and the subsequent development of dyspepsia and duodenal ulcer B. $\mathbf{H}$. NOVIS, I. N. MARKS, S. BANK, AND A. W. SLOAN
A radioisotope method of measuring intragastric volumes using the Volémetron R. A. HINDER AND C. G. BREMNER

The effects of vagotomy on the intestinal handling of water and electrolysis G. A. BUNCH AND R. SHIELDS

Adenocarcinoma of the small bowel as a complication of Crohn's disease J. D. FRANK AND B. A. SHOREY

Pain from distension of the pelvic colon by inflating a balloon in the irritable colon syndrome JAMES RITCHIE

Mobilization of tissue kallikrein in inflammatory disease of the colon I. J. ZEITLIN AND A. N. SMITH

Fibreoptic examination of the colon: a review of 255 cases R. H. TEAGUE, P. R. SALMON, AND A. E. READ

\section{Technique}

A technique of intestinal intubation with the fiberoptic endoscope REED T. KELLER

Progress report Intestinal parasites R. KNIGHT, M. G. SCHULTZ, D. W. HOSKINS, AND P. D. MARSDEN

Notes and activities

Copies are still available and may be obtained from the PUBLISHING MANAGER,

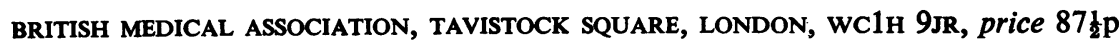

